\title{
Experimento didático de baixo custo para determinação do perfil de temperatura de uma aleta exposta ao ar ambiente
}

\author{
A low-cost didactic module for temperature profile \\ determination of a fin exposed to ambient air
}

\author{
Renato Letizia Garcia \\ Marco César Sauer ${ }^{2}$ \\ Rafael Aislan Amaral ${ }^{3}$ \\ Jorge Rodolfo Silva Zabadal ${ }^{4}$
}

\section{Resumo}

$\mathrm{O}$ artigo descreve um experimento didático de baixo custo, no qual as temperaturas numa aleta, exposta ao ambiente, convecção natural e regime permanente, são registradas com câmera termográfica. Para a realização dos ensaios, foi confeccionado um equipamento constituído por uma caixa de isopor e uma haste cilíndrica de alumínio, pintada de preto, engastada nessa caixa. A porção inserida na caixa ficou imersa em um banho de água com temperatura controlada, e o perfil de temperatura na porção exposta ao ar foi determinado. Os dados experimentais foram confrontados com valores previstos, no modelo teórico tradicional, que considera apenas a transferência convectiva de calor na superfície da aleta e, com um modelo modificado, no qual também é computada a transferência radiante de calor nessa superfície. Os resultados obtidos indicam a necessidade de considerar a transferência de calor por radiação e a adequabilidade da metodologia proposta na determinação do perfil de temperatura em aletas e do emprego do experimento para fins didáticos.

Palavras-chave: Aletas. Convecção do calor. Radiação do calor.

\begin{abstract}
The article describes a low-cost didactic experiment, in which the temperatures in a fin, exposed to ambient, natural convection and steady-state, are recorded with a thermographic camera. In order to carry out the tests, it was built an equipment consisting of an expanded polystyrene box and a cylindrical aluminum rod, painted black, embedded in this box. The inserted portion in the box was immersed in a temperature-controlled water bath, and the temperature profile of the portion exposed to air was determined. The experimental data were compared to predicted values, in the traditional theoretical model, which considers only convective heat transfer on the fin surface, and with a modified model, in which radiative heat transfer is also computed on this surface. The results obtained indicate the need to consider heat transfer by radiation and the suitability of the proposed methodology in determining the temperature profile in fins and the use of the experiment for didactic purposes.
\end{abstract}

Keywords: Fins. Heat convection. Heat radiation.

\footnotetext{
1 Doutor em Engenharia pela Universidade Federal do Rio Grande do Sul (UFRGS), Porto Alegre, RS, Brasil. Professor do PPG em Formação Docente para Ciências, Tecnologias, Engenharias e Matemática pela Universidade Estadual do Rio Grande do Sul (UERGS), Guaíba, RS. ORCID: https://orcid.org/0000-0003-2514-234X. E-mail: renato-garcia@uergs.edu.br

2 Engenheiro eletricista pela UFRGS, Porto Alegre. Professor do curso Técnico de Eletrônica da Fundação Escola Técnica Liberto Salzano Vieira da Cunha (FETLSVC), Novo Hamburgo, RS. ORCID: https://orcid.org/ 0000-0002-5758-8349. E-mail: sauer@liberato.com.br

3 Doutor em Engenharia pela Universidade Federal do Rio de Janeiro (UFRJ), Rio de Janeiro, RJ, Brasil. Professor do Departamento Interdisciplinar na UFRGS, Tramandaí, RS. ORCID: https://orcid.org/ 0000-0002-2627-7679. E-mail: rafael.amaral@ufrgs.br

4 Doutor em Engenharia pela UFRGS. Professor do Departamento Interdisciplinar na UFRGS, Tramandaí, RS. ORCID: https://orcid.org/ 0000-0002-1237-390X. E-mail: jorge.zabadal@ufrgs.br
} 


\section{Introdução}

O emprego de aletas em equipamentos industriais, sistemas de resfriamento de motores de combustão interna e processadores de computadores, entre outros, possibilita obter uma maior dissipação de calor, a partir do aumento da superfície de troca térmica. Na maioria das situações, são utilizados arranjos de aletas, que atuam como extensão da área da interface sólida em contato com o ar ambiente (AZIZ; KRAUS, 1995; RAZELOS, 2010).

O estudo da transferência de calor em superfícies estendidas (aletas) integra o conteúdo programático de disciplinas que tratam de processos de transferência de calor e massa, presentes na grade curricular de engenharia química e mecânica e cursos afins (PALMA; HORTA; SOUZA JÚNIOR, 2020).

A abordagem tradicional, apresentada em muitos livros didáticos, inicia-se com um balanço térmico diferencial em um elemento de espessura infinitesimal de uma aleta, cuja área da seção transversal é constante ao longo de sua extensão (HOLMAN, 2010). A condição de regime permanente e temperatura uniforme numa seção transversal são adotadas, sendo consideradas conjuntamente com a hipótese de que o calor é transferido da superfície exposta da aleta para o meio externo exclusivamente por convecção (ÇENGEL; GHAJAR, 2012). A resolução da equação diferencial ordinária, proveniente desse balanço, fornece uma expressão analítica do perfil unidimensional de temperatura ao longo da extensão da aleta.

Aulas expositivas, nas quais são apresentados exercícios teóricos, em cujo enunciado são fornecidos parâmetros físicos e dados geométricos de um sistema ou equipamento, são realizadas de forma recorrente no estudo da transferência de calor e massa (NEZ; SANTOS, 2017). Esses exercícios são solucionados, a partir da aplicação de princípios, leis e equações que possibilitam a obtenção do perfil de temperatura em uma aleta.

É importante ressaltar que os valores numéricos de alguns parâmetros físicos, indicados no enunciado deste tipo de questão, dentre os quais destacamos o coeficiente de película, não correspondem àqueles que se verificam num sistema físico real. Além disso, em muitas situações, a transferência de calor por radiação é relevante e deve ser computada, juntamente com a transferência convectiva, para que se possa avaliar corretamente o perfil de temperatura em uma aleta.

O presente trabalho foi desenvolvido com o objetivo de viabilizar uma estratégia de ensino desse assunto, visando a observação do comportamento térmico de um sistema físico real e a estimativa de seus parâmetros físicos, a partir de um experimento didático de baixo custo e de fácil execução. Cabe destacar que o desenvolvimento de experimentos didáticos de baixo custo voltados para o ensino de física aplicada na graduação tem se intensificado nos últimos anos (GASPAR, 2014; LIMA, 2018); e, nesse sentido, na área de transferência de calor e massa, incluem-se os trabalhos de Laburú e Rodrigues (1998) e Ludke et al. (2013). A aquisição de materiais, confecção do equipamento e a realização dos ensaios foram concebidos dentro dessa proposta. No intuito de facilitar a compreensão do trabalho desenvolvido, segue uma breve descrição das seções deste artigo.

Na seção 2, são apresentados, preliminarmente, os fundamentos teóricos relativos à transferência de calor em uma superfície estendida (aleta). Na sequência, é incorporado no balanço térmico original a contribuição do calor transferido por radiação na superfície da aleta. A equação diferencial resultante é similar àquela tradicionalmente apresentada nos livros didáticos, à exceção do fato de que o coeficiente de película a ser utilizado engloba a transferência radiativa e convectiva de calor. Dessa forma, é definido um coeficiente de película aparente, constituído pela soma do coeficiente convectivo de transferência de calor com um coeficiente associado à contribuição radiante (INCROPERA et al., 2008). Nesta seção, também são detalhados os conceitos e a formulação empregados na caracterização e estimativa desses coeficientes.

Na seção subsequente, é descrito o material utilizado, a montagem do equipamento, a relização dos ensaios e os ajustes operacionais implementados. A descrição dos resultados obtidos é apresentada na seção seguinte; confrontando-se os perfis experimentais desses ensaios com os teóricos, previstos no modelo proposto e naquele tradicionalmente utilizado, no qual é considerada apenas a transferência convectiva de calor. A discussão dos resultados é feita na seção 5 , na qual são analisadas eventuais fontes de erro e outros fatores que possam originar as discrepâncias constatadas entre os resultados obtidos nos ensaios e os valores previstos nos modelos teóricos utilizados.

$\mathrm{Na}$ última seção, são apresentadas as conclusões, apontando-se os procedimentos e cuidados necessários na confecção do equipamento e realização dos ensaios. É sugerido o planejamento de algumas atividades complementares, além da mera execução dos ensaios, visando a implementação de uma aula prática que possibilite facilitar o aprendizado e, simultaneamente, despertar o interesse do aluno sobre o assunto. 


\section{Fundamentos teóricos}

No balanço térmico aplicado em um elemento de espessura infinitesimal de uma aleta, de seção transversal constante, conforme esquema apresentado na figura 1, considera-se a condução unidimensional de calor na direção x, no interior da aleta; e, por convecção, na superfície exposta ao ambiente.

Figura 1 - Balanço térmico em um elemento de espessura infinitesimal

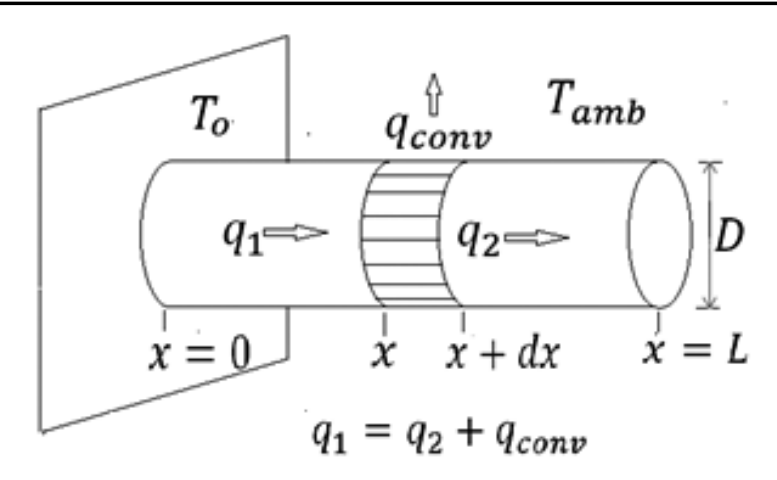

Fonte: Os autores (2021).

A condução e a convecção do calor, descritas, respectivamente, pela Lei de Fourier e pela Lei de Newton do Resfriamento, quando aplicadas nas superfícies que delimitam o elemento de espessura inifinitesimal $\mathrm{dx}$, destacado na figura 1, resultam na seguinte expressão para o balanço térmico proposto:

$$
\text { k.A. } \frac{d^{2} T}{d x^{2}}=h \cdot P .\left(T-T_{a m b}\right),
$$

na qual $T$ é a temperatura numa seção transversal e $T_{a m b}$ é a temperatura ambiente. Nessa equação, $k, h$,
$P$ e $A$ são, respectivamente, a condutividade térmica, o coeficiente convectivo de transferência de calor, o perímetro e a área da seção transversal da aleta; admitindo-se que esses quatro termos permaneçam constantes em toda a extensão da aleta. No modelo teórico proposto, admite-se regime permanente e fluxo unidimensional de calor ao longo da extensão da aleta; de modo que a temperatura é função exclusivamente de $x$, isso é, da distância da seção transversal à base da aleta (INCROPERA; DEWITT, 2014).

\subsection{Perfil de temperatura em uma aleta}

A equação (1) pode ser reescrita na forma de uma equação diferencial ordinária de segunda ordem, linear e homogênea:

$$
\frac{d^{2} \theta}{d x^{2}}-m^{2} \cdot \theta=0
$$

na qual $\theta$ é a diferença entre a temperatura, numa seção transversal da barra e a temperatura ambiente, $T-T_{a m b}$, e o termo $m$ é assim expresso:

$$
m=\sqrt{\frac{h . P}{k \cdot A}}
$$

A solução geral da equação (2) é do tipo:

$$
\theta=C_{1} \cdot e^{-m \cdot x}+C_{2} \cdot e^{-m \cdot x}
$$

na qual $C_{1}$ e $C_{2}$ são constantes arbitrárias a serem determinadas pelas condições de contorno na base e na extremidade livre da aleta. Na situação em que se considera a temperatura da base igual a $T_{0} \mathrm{e}$ transferência convectiva de calor na seção transversal da extremidade livre da aleta, teremos a equação (5), em que $L$ é o comprimento total da aleta (ÇENGEL; GHAJAR, 2012).

$$
\frac{\theta}{\theta_{0}}=\frac{T-T_{a m b}}{T_{0}-T_{a m b}}=\frac{\cosh [m \cdot(L-x)]+(h / m \cdot k) \cdot \operatorname{senh}[m(L-x)]}{\cosh (m \cdot L)+(h / m \cdot k) \cdot \operatorname{senh}(m \cdot L)}
$$

2.2 Radiação e convecção na superfície exposta da aleta

O calor transferido por radiação, por unidade de comprimento da aleta $(d x)$, pode ser incorporado no balanço térmico original da equação (1), resultando na expressão matemática da equação (6), em que $\varepsilon$ e $\sigma$ são, respectivamente, a emissividade da superfície sólida e a constante de Stefan-Boltzmann, cujo valor é $5,67 \times 10^{-8} \mathrm{~W} /\left(\mathrm{m}^{2} . \mathrm{K}^{4}\right)$. A emissividade é um valor numérico entre 0 e 1; e os valores de $T$ e $T_{a m b}$ devem ser expressos em Kelvin, quando se avalia a transferência radiativa de calor. É possível reescrever a equação (6), expandindo o produto notável de modo a se obter a equação (7).

$$
\begin{gathered}
\text { k.A. } \frac{d^{2} T}{d x^{2}}=h . P .\left(T-T_{a m b}\right)+\varepsilon \cdot \sigma \cdot P \cdot\left(T^{4}-T_{a m b}^{4}\right. \\
k . A \cdot \frac{d^{2} T}{d x^{2}}=\left[h+\varepsilon \cdot \sigma \cdot\left(T^{2}+T_{a m b}^{2}\right) \cdot\left(T+T_{a m b}\right)\right] \cdot P .\left(T-T_{a m b}\right)
\end{gathered}
$$

Cabe destacar que as equações (1) e (7) se diferenciam pelo fato de que o termo $h$ da equação
(1) é substituído, na equação (7), por uma expressão entre colchetes que engloba termos adicionais. 
Considerando um valor constante para a variável $T$, contida no interior desse colchete, e substituindo-a pelo valor médio da temperatura da aleta (assinalado como "T barra"), é possível identificar um coeficiente de película "aparente", $h_{\text {aparente }}$, correspondente à soma das contribuições radiante e convectiva de transferência de calor na aleta. As expressões que definem esse coeficiente e o coeficiente de película, associado exclusivamente à transferência radiativa de calor, $h_{r a d}$. (INCROPERA et al., 2008), são detalhadas a seguir:

$$
\begin{aligned}
h_{\text {aparente }} & =h+\varepsilon \cdot \sigma \cdot\left(\bar{T}^{2}+T_{a m b}^{2}\right) \cdot\left(\bar{T}+T_{a m b}\right) \\
h_{\text {rad }} & =\varepsilon \cdot \sigma \cdot\left(\bar{T}^{2}+T_{a m b}^{2}\right) \cdot\left(\overline{\mathrm{T}}+\mathrm{T}_{\mathrm{amb}}\right)
\end{aligned}
$$

Consequentemente, é preservada a forma original do modelo teórico proposto na equação (1), simplificando-se os cálculos, ao considerar um valor de $h_{\text {rad }}$, constante, ao longo de toda a extensão da aleta; sendo importante ressaltar que, no cálculo do valor de $h_{r a d}, T$ e $T_{a m b}$ devem ser expressos em valores de temperatura absoluta.

\subsection{Coeficiente convectivo de transferência de calor}

O coeficiente convectivo de transferência de calor ou coeficiente de película, $h$, é o parâmetro físico determinante na estimativa da taxa de transferência convectiva de calor, numa interface sólido-fluido. O valor de $h$ depende de vários fatores, dentre os quais podemos destacar a geometria da interface, as temperaturas da superfície sólida e do fluido circundante, o tipo de fluido e as características do escoamento na interface.

De modo geral, problemas envolvendo a convecção do calor são classificados conforme o tipo de escoamento (externo ou interno, natural ou forçado) e a natureza do fluido (líquido ou gasoso). Assim, em livros didáticos de transferência de calor, o estudo da convecção é subdividido em casos particulares, abordados, na maioria das vezes, em capítulos distintos (BEJAN, 1996). Na situação em análise, vamos analisar o escoamento externo em uma barra cilíndrica horizontal, exposta ao ar ambiente, em regime permanente e sob convecção natural (MUELLER; ABU-MULAWEH, 2006).

Estudos relativos à convecção natural em cilindros, em contato com o ar, foram desenvolvidos, inicialmente, a partir de investigações experimentais e analíticas e resultaram em uma série de correlações empíricas, associadas ao cálculo do número adimensional de Nusselt (Nu) (BOETCHER, 2014). Esse adimensional é uma grandeza muito utilizada na determinação do coeficiente de película; e, no caso de convecção natural, é expresso em função dos números de Rayleigh $(R a)$, Grashoff $(G r)$ e Prandtl (Pr) (ÇENGEL, GHAJAR, 2012). No experimento proposto, que envolve o escoamento externo de um fluido sobre uma geometria cilíndrica, utiliza-se a seguinte equação para o número de Nusselt:

$$
N u=\frac{h \cdot D}{k_{f}}
$$

na qual $h$ é o coeficiente de película, $D$ é o diâmetro do cilindro e $k f$ é a condutividade térmica do fluido junto à interface sólida. O número de Rayleigh, por sua vez, consiste no produto dos números de Grashoff e Prandtl, segundo a equação:

$$
R a=G r \cdot \operatorname{Pr}=\frac{g \cdot \beta \cdot \Delta T \cdot D^{3}}{v \cdot \alpha}
$$

sendo $g$ a aceleração da gravidade; $\beta$, o coeficiente de expansão térmica do fluido; $\Delta T$, a diferença entre a temperatura da aleta e do fluido; $v$, a viscosidade cinemática do fluido; e, $\alpha$, a difusividade térmica do fluido. O coeficiente de expansão térmica corresponde ao inverso da temperatura absoluta do fluido. As propriedades do fluido devem ser avaliadas a partir do valor da temperatura de filme ou película, que é igual à média aritmética entre a temperatura na superfície da aleta e a temperatura ambiente. Neste trabalho, a temperatura da superfície aleta corresponde à media aritmética entre a temperatura na base, $T_{0}$, e na extremidade livre, $T_{L}$. Dentre as correlações que permitem associar o número de Nusselt com o número de Rayleigh, vamos utilizar aquela proposta por Morgan (1975):

$$
N u=0,85 \cdot R a^{0,188} .
$$

O conjunto de equações (8) a (12) e os registros de temperatura ambiente da base e da extremidade livre da aleta são utilizados na determinação do coeficiente de película teórico, $h$, e do coeficiente de película aparente, $h_{\text {aparente }}$.

\section{Metodologia}

O equipamento foi construído, a partir de uma caixa de isopor, com comprimento, largura e altura, respectivamente, de 220x140x180mm. Nessa caixa, foi feito um orifício numa das faces e ajustado um engaste 
na face oposta, na direção do comprimento, para a introdução de uma haste cilíndrica de alumínio, com

Figura 2 - Imagem do interior da caixa de isopor, na qual se visualiza o sistema de aquecimento do banho de água e a aleta

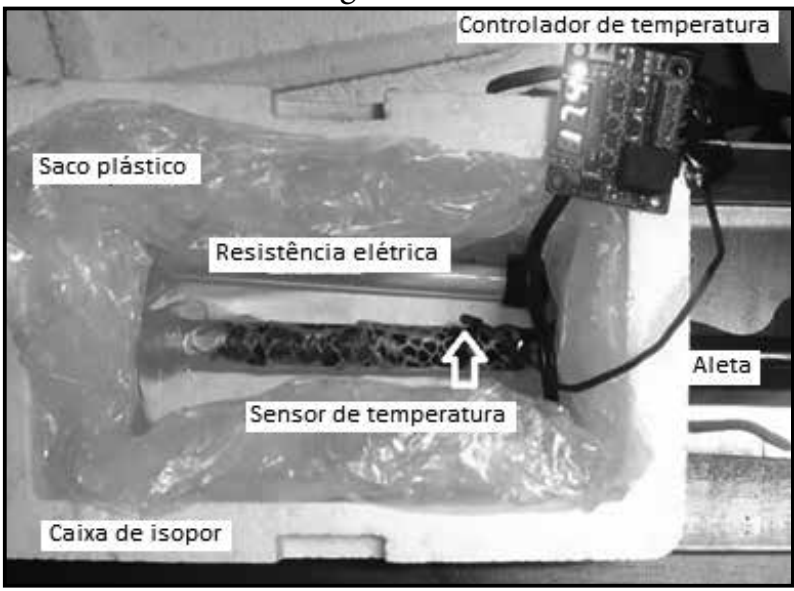

Fonte: Os autores (2021).

$15 \mathrm{~mm}$ de diâmetro e $790 \mathrm{~mm}$ de comprimento. A figura 2 ilustra a montagem realizada.

O experimento consiste na medição das temperaturas, ao longo da porção exposta da haste, que atua como uma aleta, mantida aquecida pelo contato com um banho de água, no interior da caixa. As faces internas das paredes e a porção da haste que ficou dentro da caixa de isopor foram revestidos com um saco plástico, cuja finalidade é evitar vazamentos de água, através dessas paredes, que ocorrem em temperaturas superiores a $70^{\circ} \mathrm{C}$, principalmente na região atravessada pela haste.

A haste cilíndrica utilizada consiste de liga de alumínio 6063, cuja condutibilidade térmica é de $200,6 \mathrm{~W} / \mathrm{m} . \mathrm{K}$, e foi pintada com tinta spray fosca, na cor preta. $\mathrm{O}$ banho é aquecido com uma resistência elétrica de $200 \mathrm{~W}$, do tipo utilizado em aquários, sendo mantido na temperatura desejada, através de um controlador NTC, modelo W1 209.

No intuito de minimizar a influência de perturbações por correntes de ar, no escoamento induzido pelo aquecimento da aleta, foi acoplada uma estrutura de acrílico, constituída por placas laterais, com $100 \mathrm{~mm}$ de altura, ao longo de toda a extensão da haste, posicionadas $10 \mathrm{~mm}$, acima da base da caixa de isopor. Dessa forma, o eixo central da aleta fica posicionado a $60 \mathrm{~mm}$ de altura da base da caixa e centralizado, em relação às placas laterais. Na extremidade dessas placas, foi inserida uma chapa de acrílico retangular e cantoneiras de reforço, unindo as duas placas e servindo de apoio à extremidade livre da haste de alumínio, conforme ilustrado na figura 3 .

Figura 3 - Imagem externa do equipamento confeccionado, na qual se visualizam as placas de acrílico, ao lado da haste; e a câmera térmica, fixada num tripé e acoplada a um trilho

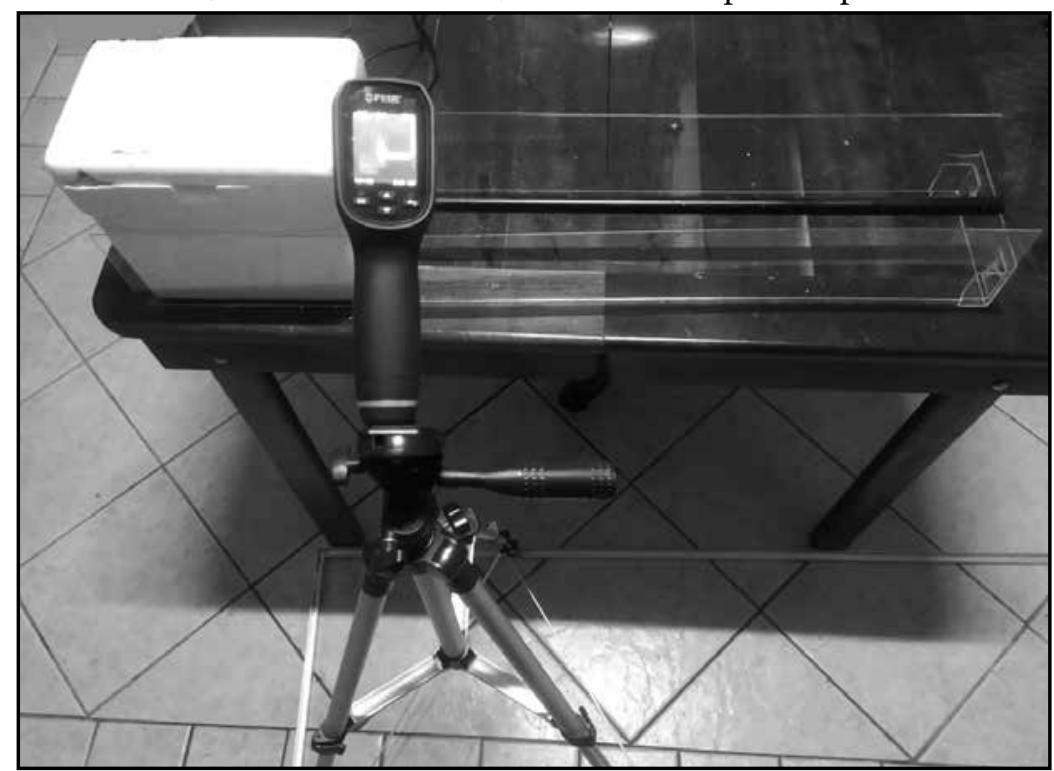

Fonte: Os autores (2021).

As medições de temperatura foram realizadas com câmera térmica da marca FLIR, modelo TG165, que efetua a medição sem contato. Foram registradas, em todos os ensaios, as temperaturas em 30 pontos, sendo a distância de cada ponto até a base da aleta, indicada na tabela 1 . A necessidade de realizar a medição nesses pontos levou os autores a posicionar a câmera em um tripé, que se deslocava 
em um trilho sobre o piso. Nesse trilho, foram feitas as marcações dessas distâncias; sendo possível, desta forma, manter a câmera imóvel e registrar a temperatura no ponto desejado.

Tabela 1 - Distância dos pontos de medição de temperatura até a base da aleta

\begin{tabular}{ccccccccccc}
\hline Ponto & $\mathbf{1}$ & $\mathbf{2}$ & $\mathbf{3}$ & $\mathbf{4}$ & $\mathbf{5}$ & $\mathbf{6}$ & $\mathbf{7}$ & $\mathbf{8}$ & $\mathbf{9}$ & $\mathbf{1 0}$ \\
\hline Distância $(\mathrm{m})$ & 0,00 & 0,01 & 0,02 & 0,03 & 0,04 & 0,05 & 0,06 & 0,07 & 0,08 & 0,09 \\
Ponto & $\mathbf{1 1}$ & $\mathbf{1 2}$ & $\mathbf{1 3}$ & $\mathbf{1 4}$ & $\mathbf{1 5}$ & $\mathbf{1 6}$ & $\mathbf{1 7}$ & $\mathbf{1 8}$ & $\mathbf{1 9}$ & $\mathbf{2 0}$ \\
Distância $(\mathrm{m})$ & 0,10 & 0,12 & 0,14 & 0,16 & 0,18 & 0,20 & 0,22 & 0,24 & 0,26 & 0,28 \\
Ponto & $\mathbf{2 1}$ & $\mathbf{2 2}$ & $\mathbf{2 3}$ & $\mathbf{2 4}$ & $\mathbf{2 5}$ & $\mathbf{2 6}$ & $\mathbf{2 7}$ & $\mathbf{2 8}$ & $\mathbf{2 9}$ & $\mathbf{3 0}$ \\
Distância $(\mathrm{m})$ & 0,30 & 0,33 & 0,36 & 0,39 & 0,42 & 0,45 & 0,48 & 0,51 & 0,54 & 0,57 \\
\hline
\end{tabular}

Fonte: Os autores (2020).

A câmera térmica utilizada efetua a medição da temperatura em um ponto do objeto com base na radiação emitida, sendo necessário indicar a emissividade da superfície. Na figura 4, são apresentadas imagens da câmera (a) e do visor (b), no qual consta, além da temperatura registrada, o valor da emissividade. A câmera utilizada permite ajustar valores de emissividade na faixa de 0,05 a 0,95 , com intervalos de 0,05 .

Figura 4 - Imagem da câmera térmica (a) e do seu visor (b), no qual, além do registro de temperatura, consta o valor da emissividade indicada para a superfície

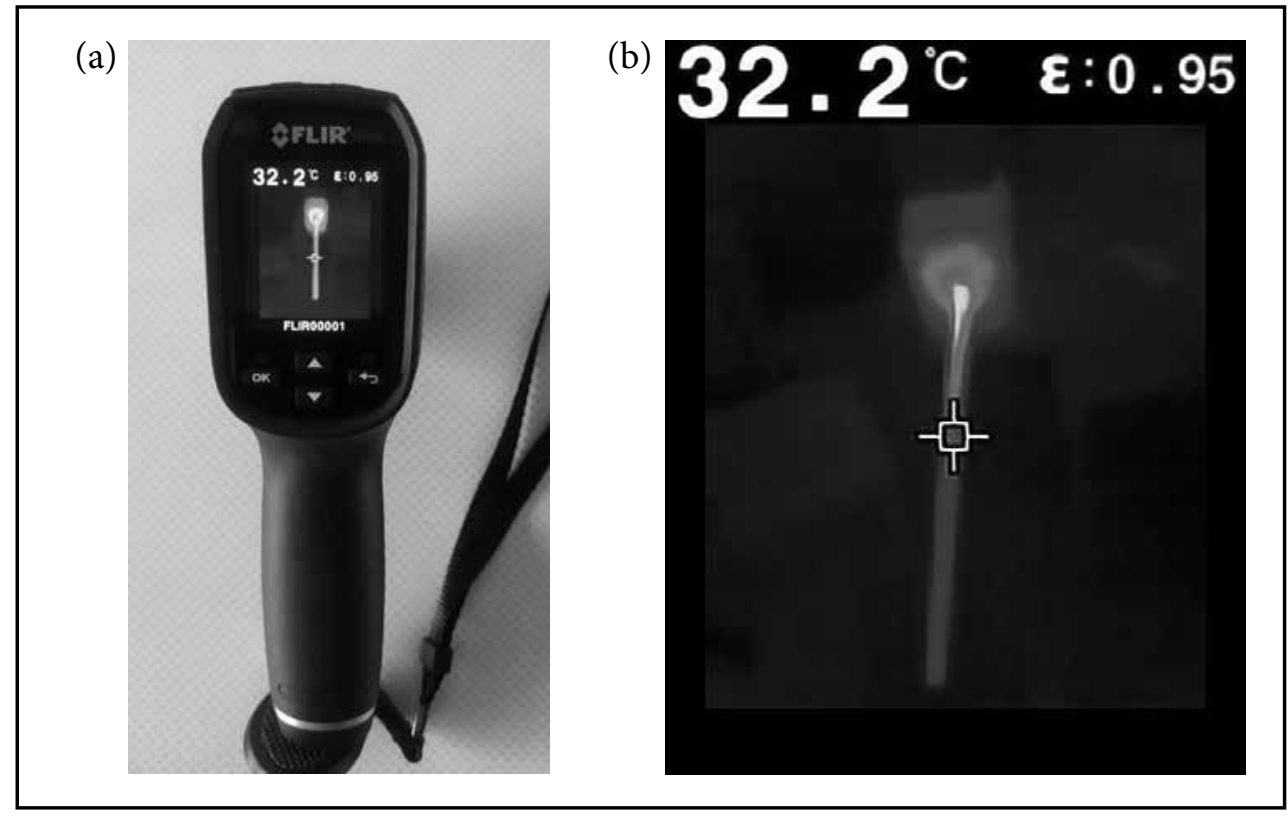

Fonte: Os autores (2021).

Superfícies pintadas com tinta preta fosca possuem emissividade igual a 0,97 (WOLFE, ZISSIS, 1978). A Lei de Stefan-Boltzmann estabelece que a taxa de transferência radiativa de calor é proporcional à emissividade da superfície; assim, visando aumentar a contribuição radiativa no calor total dissipado na superfície da aleta, a haste de alumínio foi pintada nessa cor.

O quadro 1 indica as características e custos dos materiais e instrumentos, utilizados na confecção do equipamento. O custo total calculado é muito reduzido, principalmente, quando comparado a módulos didáticos comerciais similares e com a mesma finalidade. A câmera térmica, item mais caro, é um equipamento portátil, o que possibilita a sua obtenção mediante empréstimo, minimizando, de forma acentuada, os custos envolvidos na realização do experimento didático proposto. 
Quadro 1 - Características e custos dos materiais e instrumentos utilizados nos ensaios

\begin{tabular}{|c|c|c|}
\hline Materiais e instrumentos & Quantidade & Custo (R\$) \\
\hline Caixa de isopor & 1 & 6,00 \\
\hline Controlador de temperatura NTC, modelo W1 209 & 1 & 25,00 \\
\hline Resistência elétrica, potência 200 W & 1 & 40,00 \\
\hline Fonte de alimentação 12V & 1 & 15,00 \\
\hline Barra de alumínio (750mm x 15mm) & 1 & 36,00 \\
\hline Câmera térmica FLIR, modelo TG165 & 1 & $2.500,00$ \\
\hline Estrutura de acrílico & 1 & 80,00 \\
\hline Tripé & 1 & 60,00 \\
\hline Trilho de alumínio & 1 & 30,00 \\
\hline Lata de tinta spray preta, fosca, para altas temperaturas & 1 & 25,00 \\
\hline TOTAL & & $\mathbf{2 . 8 0 3 , 0 0}$ \\
\hline
\end{tabular}

Fonte: Os autores (2020).

Com objetivo de minimizar os erros experimentais, foram efetuados diversos testes, o que possibilitou o ajuste do equipamento e a otimização das condições operacionais. Dessa forma, os ensaios finais foram realizados nas temperaturas de 55, 60, $65,70,75,80$ e $85^{\circ} \mathrm{C}$, sendo estabelecido um tempo de espera de 30 minutos, após o banho atingir a temperatura do ensaio, para iniciar-se as medições de temperatura ao longo da aleta.

$\mathrm{Na}$ tabela 2, são identificadas as condições operacionais de cada ensaio, caracterizados pela temperatura ambiente, $T_{a m b}$, e do banho de água, $T_{\text {banho; }}$ além das temperaturas registradas nas extremidades da aleta, $T_{0}$ e $T_{L}$. A temperatura média da aleta, $T_{\text {média }}$, e a temperatura de filme, $T_{\text {filme }}$, são calculadas conforme detalhado no penúltimo parágrafo da seção 2. Os valores do coeficiente de película teórico e do coeficiente de película aparente, $h \mathrm{e}$ $h_{\text {aparente }}$, para cada um dos ensaios realizados, também foram inseridos nessa tabela.

Tabela 2 - Condições operacionais e valores calculados para os coeficientes de película

\begin{tabular}{ccccccccc}
\hline Ensaio & $\begin{array}{c}\mathbf{T}_{\text {banho }} \\
.\left({ }^{\circ} \mathrm{C}\right)\end{array}$ & $\begin{array}{c}\mathbf{T}_{\mathbf{0}} \\
.\left({ }^{\circ} \mathrm{C}\right)\end{array}$ & $\begin{array}{c}\mathbf{T}_{\mathbf{L}} \\
.\left({ }^{\circ} \mathrm{C}\right)\end{array}$ & $\begin{array}{c}\mathbf{T}_{\text {média }} \\
.\left({ }^{\circ} \mathrm{C}\right)\end{array}$ & $\begin{array}{c}\mathbf{T}_{\text {filme }} \\
.\left({ }^{\circ} \mathrm{C}\right)\end{array}$ & $\begin{array}{c}\mathbf{T}_{\text {amb }} \\
.\left({ }^{\circ} \mathrm{C}\right)\end{array}$ & $\begin{array}{c}\mathbf{h} \\
\left(\mathrm{W} / \mathrm{m}^{2} . \mathrm{K}\right)\end{array}$ & $\begin{array}{c}\mathbf{h}_{\text {aparente }} \\
\left(\mathrm{W} / \mathrm{m}^{2} . \mathrm{K}\right)\end{array}$ \\
\hline I & 55 & 44,3 & 24,1 & 34,20 & 27,55 & 20,9 & 7,05 & 12,90 \\
II & 60 & 47,4 & 24,7 & 36,05 & 28,48 & 20,9 & 7,22 & 13,13 \\
III & 65 & 50,4 & 22,5 & 36,45 & 27,48 & 16,5 & 7,61 & 13,41 \\
IV & 70 & 56,4 & 27,1 & 41,75 & 31,37 & 21,0 & 7,66 & 13,74 \\
V & 75 & 57,4 & 21,7 & 39,55 & 27,73 & 15,9 & 7,86 & 13,73 \\
VI & 80 & 61,0 & 22,6 & 41,80 & 28,60 & 15,4 & 8,02 & 13,94 \\
VII & 85 & 73,4 & 26,3 & 49,85 & 33,17 & 16,5 & 8,37 & 14,57 \\
\hline
\end{tabular}

Fonte: Os autores (2020).

\section{Resultados obtidos}

Os dados experimentais obtidos em cada ensaio foram plotados num gráfico, relacionando a temperatura registrada em vários pontos, ao longo de toda a extensão da aleta, com a distância do ponto até a base da aleta. A partir dos dados relativos à geometria $\mathrm{e}$ condutividade térmica da aleta; e dos valores de $T_{0}, T_{L}$ e $T_{a m b}$, referentes a cada ensaio, foram calculados os coeficientes $h$ e $h_{\text {rad }}$, mediante o emprego das equações (8) a (12). Os valores de $h$ e $h_{\text {aparente }}$ resultantes foram inseridos nas equações (3) e (5), de modo a obter o valor teórico da temperatura, ao longo da aleta, nas hipóteses associadas aos modelos teóricos discutidos, isto é:

i. calor transferido exclusivamente por convecção na superfície da aleta; 
ii. calor transferido simultaneamente, por convecção e radiação, na superfície da aleta.

A figura 5 apresenta gráficos com perfis de temperatura dos ensaios I e III, acima e abaixo, respectivamente. Neles, foi inserida a curva relativa à média dos dados experimentais; e, também, as curvas com as previsões dos perfis teóricos de temperatura associados às condições “i” e "ii”.

Figura 5 - Perfis de temperatura, relativos aos ensaios I e III, nos gráficos apresentados acima e abaixo, respectivamente

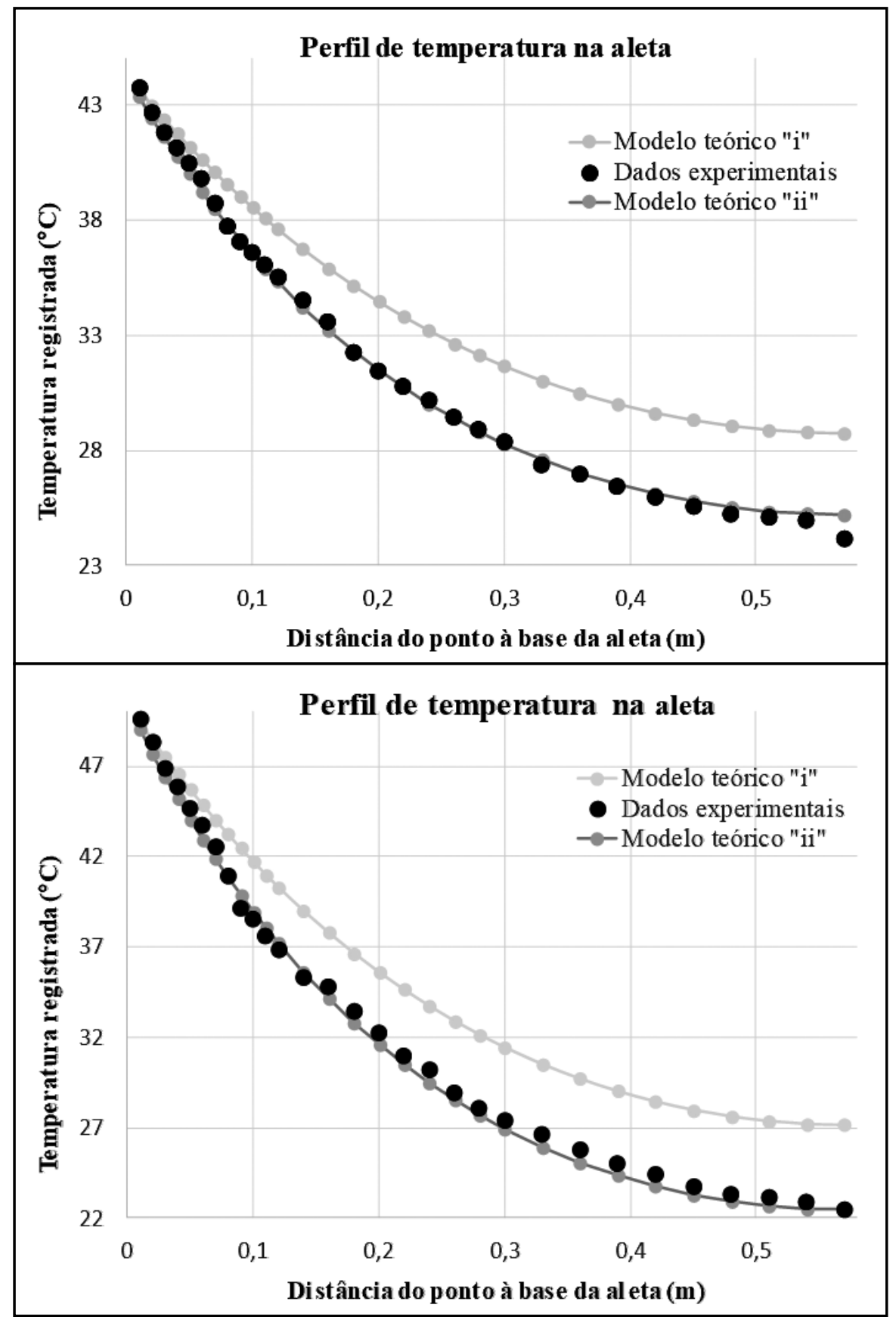

Fonte: Os autores (2021).

No intuito de quantificar os desvios constatados entre dados experimentais e valores teóricos, foi calculada a média aritmética das diferenças entre eles nos pontos de registro de temperatura, ao longo da aleta. Os autores, visando avaliar a oscilação dos valores experimentais, em relação às previsões teóricas, 
calcularam também a média aritmética das diferenças absolutas, obtidas nesses pontos. Dessa forma, quando os valores dessas duas médias são distintos, é possível caracterizar desvios maiores e menores que zero, na comparação realizada entre o perfil teórico e experimental. Na tabela 3, são apresentados os valores médios das diferenças, obtidas nos ensaios realizados, sendo que as letras " $\mathrm{A}$ " e "B" indicam, respectivamente, as médias das diferenças normais e absolutas, nas formulações "i" e "ii".

Tabela 3 - Média aritmética das diferenças normais e absolutas entre dados experimentais e valores teóricos, nas formulações indicadas em "i" e "ii"

\begin{tabular}{ccccc}
\hline & \multicolumn{2}{c}{ Convecção } & \multicolumn{2}{c}{ Convecção + Radiação } \\
\hline Ensaio & A & B & A & B \\
\hline I & 2,59 & 2,49 & $-0,03$ & 0,22 \\
II & 2,74 & 2,80 & $-0,07$ & 0,46 \\
III & 3,03 & 3,04 & $-0,36$ & 0,52 \\
IV & 3,69 & 3,72 & 0,04 & 0,80 \\
V & 4,20 & 4,29 & 0,12 & 0,75 \\
VI & 4,28 & 4,39 & $-0,15$ & 0,46 \\
VII & 4,15 & 4,15 & $-1,36$ & 1,36 \\
\hline
\end{tabular}

Fonte: Os autores (2020).

\section{Discussão dos resultados}

Os gráficos apresentados na figura 5 apontam que os perfis teóricos de temperaturas, associados à formulação "ii", nas condições operacionais indicadas na tabela 2, representam de forma mais adequada os resultados obtidos nos ensaios do que os perfis teóricos associados à formulação "i".

Cabe destacar o fato de que os valores de $h_{\text {aparente }}$ são bem maiores que os correspondentes valores de $h$, conforme indicado na tabela 2; sendo possível constatar, ainda, que o coeficiente de película associado à contribuição radiante é da mesma magnitude que o coeficiente de película teórico. Consequentemente, a contribuição radiativa é relevante e não pode ser desprezada na transferência de calor, em aletas expostas ao ar ambiente, em regime permanente e sob convecção natural, na faixa de temperatura na qual os ensaios foram realizados.

Segundo Mueller e Abu-Mulaweh (2006), a contribuição radiante é da ordem de 15 a $20 \%$ do total de calor transferido em uma aleta cilíndrica horizontal longa, exposta ao ar ambiente. A contribuição radiante pode ser ainda maior, se a emissividade da superfície exposta ao ar for elevada. Em trabalhos, envolvendo a dissipação de calor em um objeto sólido aquecido e exposto ao ar ambiente, sob convecção natural, quando se despreza a contribuição radiante na transferência do calor, o coeficiente convectivo de transferência de calor obtido experimentalmente pode ser significativamente maior que seu valor teórico, sendo tipicamente superior a 30\% (MIRANDA JÚNIOR; GONÇALVES, 2016). De outra forma, quando se incorpora a contribuição radiante no cômputo do calor transferido na interface sólida, as diferenças são significativamente menores, sendo tipicamente inferiores a 20\% (GARCIA et al., 2017).

Nos resultados apresentados na tabela 3, à exceção do ensaio VII, os valores das diferenças médias normais e absolutas, na condição "ii", são significativamente distintos, caracterizando a oscilação do perfil experimental sobre a curva correspondente ao perfil teórico de temperaturas e indicando desvios de natureza aleatória. Tais desvios podem estar associados à precisão do instrumento de medição de temperatura utilizado, deslocamentos do ponto de registro da temperatura, em relação à posição desejada, flutuações de temperatura ao longo das aletas, entre outros. Correntes de ar, próximas ao equipamento, podem modificar as condições de escoamento do ar aquecido junto à interface sólida; e, consequentemente, modificar o valor do coeficiente de película e da taxa de transferência convectiva de calor.

Nesse ponto cabe ressaltar que, além dos erros aleatórios citados, as simplificações utilizadas no modelo teórico contribuem para o aumento das discrepâncias entre os registros e a distribuição teórica de temperaturas na aleta. Dentre as simplificações adotadas, o emprego de uma temperatura média ao longo de toda a aleta, no cálculo do coeficiente 
de película associado à contribuição radiativa, a princípio, é aquela que introduz maiores erros, principalmente quando a aleta está numa temperatura mais elevada.

No que diz respeito ao modelo teórico utilizado, também é importante observar que existe uma limitação nas próprias formulações unidimensionais, que não foi até então considerada. Quando se caracteriza uma aleta cilíndrica como um objeto unidimensional, isso implica, na prática, que sua dimensão axial é muito maior do que seu raio. Sendo seu raio muito pequeno em relação ao comprimento, a componente radial do gradiente de temperatura é muito superior à respectiva componente axial. Isso ocorre porque tende a surgir uma diferença significativa entre as temperaturas nas coordenadas central $(r=0)$ e na superfície da aleta $\left(r=r_{0}\right.$, sendo $r_{0}$ o raio da aleta) que é muito próxima ao próprio centro. Assim, a formulação de um balanço de energia térmica, para o qual a única componente do gradiente de temperatura a considerar seja precisamente a axial, pode produzir erros significativos. Essa ressalva justifica o fato de que, no cálculo do coeficiente de película aparente, o emprego de uma temperatura média constante, ao longo do comprimento da aleta, não constitui uma aproximação grosseira.

De fato, a principal causa de erro, verificada na abordagem clássica de problemas dessa natureza, não se deve à formulação da equação diferencial, mas da respectiva condição de contorno. Essa causa de erro reside precisamente no fato de que a condição de contorno usualmente empregada, não contempla a contribuição da transferência de calor por radiação entre o meio externo e a superfície da aleta. Esse argumento será discutido, em maior nível de detalhe, em um trabalho futuro, já em fase de conclusão, que utiliza uma versão bidimensional da equação de transferência de calor por condução em regime estacionário. Por ora, o aspecto mais importante a ressaltar é o fato de que a contribuição radiante, para o coeficiente de película, não deve ser negligenciada, mesmo para temperaturas moderadas.

É importante ressaltar que as diferenças médias normais, indicadas na coluna A, na condição "ii", são, com exceção do último ensaio, inferiores a 0,4 graus Celsius; sendo tal valor significativamente baixo, tendo em vista o equipamento e os instrumentos de medição utilizados. As diferenças médias absolutas, nessa condição, são inferiores a um grau, evidenciando a viabilidade da metodologia proposta e do equipamento utilizado na realização de um estudo experimental da transferência de calor em aletas.

\section{Conclusões}

A incorporação da contribuição radiante no balanço térmico utilizado para avaliar a distribuição de temperaturas em uma aleta cilíndrica longa, sob convecção natural, possibilita obter resultados experimentais condizentes com o modelo teórico proposto.

As discrepâncias entre os perfis experimentais e teóricos de temperatura, quando a contribuição radiante é incorporada no modelo, são significativamente baixas, com um desvio médio igual a $0,65^{\circ} \mathrm{C}$, considerando-se o valor absoluto das diferenças verificadas em todos os ensaios realizados.

A obtenção de um resultado quantitativo satisfatório, com pouca discrepância entre perfis teóricos e experimentais de temperatura, só foi possível devido a uma série de procedimentos adotados na confecção do equipamento e na realização dos ensaios. A utilização de placas de acrílico, nas laterais da aleta, recortadas de modo a isolar o entorno da aleta de correntes de ar que pudessem afetar a convecção natural induzida pelo aquecimento de sua superfície, bem como a utilização de um trilho, para posicionar a câmera termográfica e a vedação, com emprego de silicone, da região de contato entre a aleta e a parede da caixa de isopor, foram implementações necessárias para a minimização dos erros experimentais. O emprego de uma aleta de cor preta e fosca, cuja emissividade é próxima de 1, permitiu reduzir a incerteza associada ao valor desse parâmetro; e, consequentemente, a incerteza no valor estimado da transferência radiativa de calor.

A utilização da metodologia proposta e do equipamento confeccionado é uma estratégia didática, de cunho experimental, que visa ressaltar a necessidade de considerar o mecanismo de transferência radiante de calor em aletas sob convecção natural, mesmo em temperaturas próximas ou ligeiramente superiores à temperatura ambiente. Nesse contexto, a análise do balanço térmico diferencial e dos números adimensionais na convecção natural integra o estudo de um problema físico real, que requer a participação ativa dos alunos na realização dos ensaios e na elaboração de relatórios sobre o experimento executado, incentivando-os na aprendizagem desses tópicos.

Finalmente, os autores destacam que a participação ativa dos alunos, bem como seu aprendizado, a partir da proposição de um experimento didático, necessita, além de um resultado quantitativo satisfatório e condizente com o comportamento de um sistema físico real, um planejamento adequado. Nesse sentido, o docente deverá despertar o interesse do 
aluno, a partir do conhecimento prévio que ele possui sobre o tema. Dessa forma, visando uma maior eficiência no aprendizado, deverão ser inseridas atividades complementares à realização dos ensaios, com o emprego de recursos variados, dentre os quais se incluem questionários individuais, vídeos explicativos dos fenômenos a serem observados e, também, debates prévios e posteriores à execução desses ensaios.

\section{Referências}

AZIZ, A.; KRAUS, A. D. Transient heat transfer in extended surfaces. Applied Mechanics Reviews, v. 48, n. 7, p. 317-350, 1995. DOI: 10.1115/1.3005105.

BEJAN, A. Transferência de calor. São Paulo: Edgard Blücher, 1996. $570 \mathrm{p}$.

BOETCHER, S. K. S. Natural convection from circular cylinders. New York: Springer, 2014. 48 p.

ÇENGEL, Y. A.; GHAJAR, A. J. Transferência de calor e massa: uma abordagem prática. 4. ed. Porto Alegre: McGrall-Hill, 2012.

GARCIA, R. L. et al. Resfriamento de um cilindro de aço: estudo experimental da convecção e radiação do calor. Revista Brasileira de Ensino de Física, v. 39, n. 4, 2017. DOI: 10.1590/1806-9126-rbef-2017-0026.

GASPAR, A. Atividades experimentais no ensino de física: uma nova visão baseada na teoria de Vigotski. São Paulo: Livraria da Física, 2014. 250 p.

HOLMAN, J. P. Heat transfer. 10th ed. New York: McGraw-Hill, 2010.

INCROPERA, F.; DEWITT, D. P. Fundamentos de transferência de calor e de massa. 7. ed. Rio de Janeiro: LTC, 2014.

INCROPERA, F. P. et al. Fundamentos de transferência de calor e massa. Rio De Janeiro: LTC, 2008.

LABURÚ, C. E.; RODRIGUES, R. Laboratório caseiro: calorímetro de baixo custo. Caderno Catarinense de Ensino de Física, v. 15, n. 3, p. 319-322, 1998.

LIMA, S. S. Conhecimento especializado de professores de física: uma proposta de modelo teórico. 2018. 293 f. Dissertação (Mestrado em
Ensino) - Instituto Federal de Educação, Ciência e Tecnologia de Mato Grosso, Cuiabá, 2018.

LUDKE, E. et al. Um experimento para ensino de conceitos de transferência de calor em laboratório de física. Revista Brasileira de Ensino de Física, v. 35, n. 1, p. 1503-1506, 2013. DOI: 10.1590/S180611172013000100019 .

MIRANDA JÚNIOR, E. J. P.; GONÇALVES, R. S. Determinação experimental do coeficiente de transferência de calor por convecção. Revista IFES Ciência, v. 2, n. 1, p. 53-71, 2016. DOI: 10.36524/ ric.v2i1.250.

MORGAN, V. T. The overall convective heat transfer from smooth circular cylinders. Advanced Heat Transfer, v. 11, p. 199-264, 1975. DOI: 10.1016/ S0065-2717(08)70075-3.

MUELLER, D. W.; ABU-MULAWEH, H. I. Prediction of the temperature in a long horizontal fin rod cooled by natural convection and radiation. Applied Thermal Engineering, v. 26, n. 14-15, p. 1662-1668, 2006. DOI: 10.1115/IMECE2004-60243.

NEZ, E.; SANTOS, C. A. Reflexões sobre a metodologia das aulas expositivas na educação básica e superior. RELVA, v. 4, n. 1, p. 24-36, 2017.

PALMA, G. M.; HORTA, A. C. L.; SOUZA JÚNIOR, R. S. Engenharia a distância: experimento remoto sobre transferência de calor em aletas. In: CONGRESSO INTERNACIONAL DE EDUCAÇÃO E TECNOLOGIAS; ENCONTRO DE PESQUISADORES EM EDUCAÇÃO A DISTÂNCIA, São Carlos, 2020. Anais [...]. Disponível em: https:// cietenped.ufscar.br/submissao/index.php/2020/ article/view/1614. Acesso em: 22 jul. 2021.

RAZELOS, P. A critical review of extended surface heat transfer. Heat Transfer Engineering, v. 24. n. 6, p. 11-28, 2010. DOI: 10.1080/714044411. Disponível em: https://doi.org/10.1080/714044411. Acesso em: 11 ago. 2021.

WOLFE, W. L.; ZISSIS, G. J. The infrared handbook. Washington, D.C.: Office of Naval Research: Department of Navy, 1978. 
